\title{
Anesthetic Considerations in Pediatric Patients Undergoing Cochlear Implantation Surgery
}

\author{
Rahul SS ${ }^{1}$, Senthil K Anandan², E Kathiravan ${ }^{3}$
}

\begin{abstract}
Cochlear implants have resulted in effective treatment of hearing loss in children. It is mainly associated with minimal surgical complications. As this occurs at a very early age, most are associated with congenital anomalies and other defects and syndromes which should also be taken into consideration. Anxiety reduction also plays a major role. The anesthetic technique should be able to provide a bloodless field and do not affect the cochlear implant. Postoperative complications like postoperative nausea and vomiting are common.

Keywords: Anesthesia, Children, Cochlear implant, Sensorineural deafness.

Research and Innovation in Anesthesia (2021): 10.5005/jp-journals-10049-0105
\end{abstract}

\section{INTRODUCTION}

A cochlear implant is an electronic device that is used to restore hearing in patients with bilateral severe sensorineural deafness. Children are the most common candidates for cochlear implant surgery. But many characteristics make general anesthesia challenging to the pediatric population than adults. This includes short and smaller airways, larger tongue, altered metabolism and distribution of drugs, ${ }^{1}$ anterior larynx, etc. Children can come with coexisting conditions including congenital diseases, facial and airway anomalies, other medical and systemic infections, and other genetic syndromes. Along with this, they are likely to suffer from many difficulties some of them include difficulty gaining venous access, unexpected difficulties in the airway, nausea, and vomiting following surgery. They may also suffer from serious respiratory complications like laryngospasm, postoperative croup, bronchospasms, and aspirations. ${ }^{2,3}$

\section{Case Description}

A 3 1/2-year-old female child weighing $13 \mathrm{~kg}$ with a history of not responding to sounds since birth and inability to speak was diagnosed with bilateral sensorineural hearing loss and was planned for cochlear implantation. On examination, there were no associated congenital abnormalities ${ }^{4}$ or syndromic facies. On investigating blood investigations were within normal limits, ECGnormal sinus rhythm, within normal limits, X-ray chest-normal and ECHO did not show any congenital abnormalities. The patient was assessed under ASA PS1.

\section{Anesthetic Management}

On the day of surgery, an IV line was started on the dorsum of the right hand with 22-G IV cannula standard anesthetic monitors were used. The child has given Injection glycopyrrolate $0.1 \mathrm{mg}$, Inj. midazolam $0.5 \mathrm{mg}$, Inj. fentanyl $25 \mu \mathrm{g}$, and Inj. dexamethasone $4 \mathrm{mg}$ intravenously. Preoxygenation with $100 \% \mathrm{O}_{2}$ for 3 minutes. Anesthesia induced with injection propofol $35 \mathrm{mg}$ and Inj. atracurium $10 \mathrm{mg}$, intubated with $4.0 \mathrm{~mm}$ size cuffed endotracheal tube (Figs 1 and 2). Anesthesia was maintained with $\mathrm{N}_{2} \mathrm{O}: \mathrm{O}_{2}$ 2:2 along with sevoflurane at an end-tidal concentration of 1.0-1.2. Intraoperative facial nerve monitoring was performed. Anesthesia
${ }^{1-3}$ Department of Anesthesia, Shri Sathya Sai Medical College and Research Institute, Kancheepuram, Tamil Nadu, India

Corresponding Author: Senthil K Anandan, Department of Anesthesia, Shri Sathya Sai Medical College and Research Institute, Kancheepuram, Tamil Nadu, India, Phone: +91 9566567083, e-mail: dr. senthilkumar1989@gmail.com

How to cite this article: SS Rahul, Anandan SK, Kathiravan E. Anesthetic Considerations in Pediatric Patients Undergoing Cochlear Implantation Surgery. Res Inno in Anesth 2021;6(2):46-48.

Source of support: Nil

Conflict of interest: None

was maintained with propofol infusion for a short time withholding muscle relaxant and enabling the surgeon to elicit the reflexes. Hypothermia was prevented using forced air warmer. The patient maintained stable intraoperative hemodynamic parameters and was uneventful. The duration of surgery was $21 / 2$ hours with blood loss $<50 \mathrm{~mL}$. The child was given $300 \mathrm{~mL}$ of ringer lactate $(\mathrm{RL})$ during the procedure. Injection ondansetron $2 \mathrm{mg}$ was given 40 minutes before the end of the procedure.

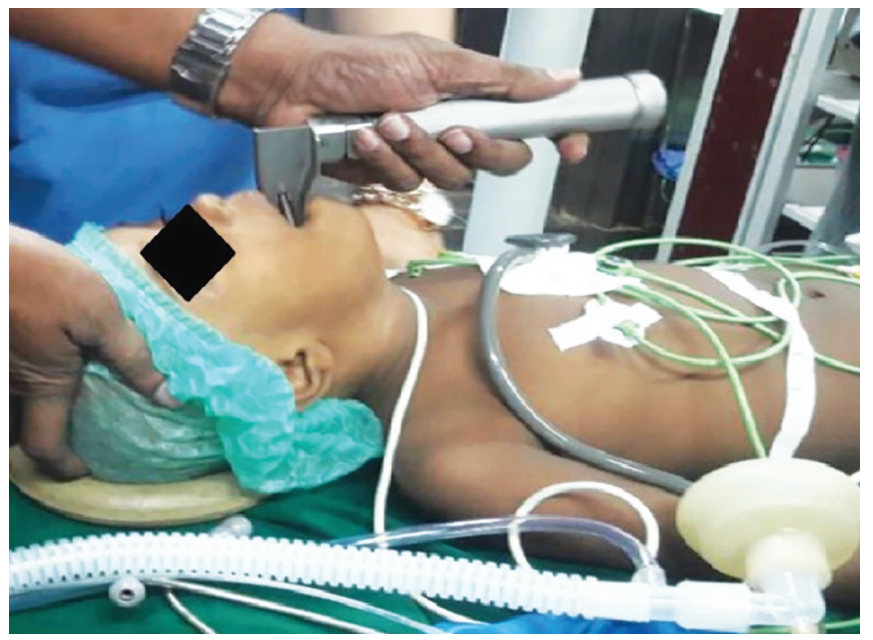

Fig. 1: Intubation of the pediatric patient

(c) The Author(s). 2021 Open Access This article is distributed under the terms of the Creative Commons Attribution 4.0 International License (https://creativecommons. org/licenses/by-nc/4.0/), which permits unrestricted use, distribution, and non-commercial reproduction in any medium, provided you give appropriate credit to the original author(s) and the source, provide a link to the Creative Commons license, and indicate if changes were made. The Creative Commons Public Domain Dedication waiver (http://creativecommons.org/publicdomain/zero/1.0/) applies to the data made available in this article, unless otherwise stated. 


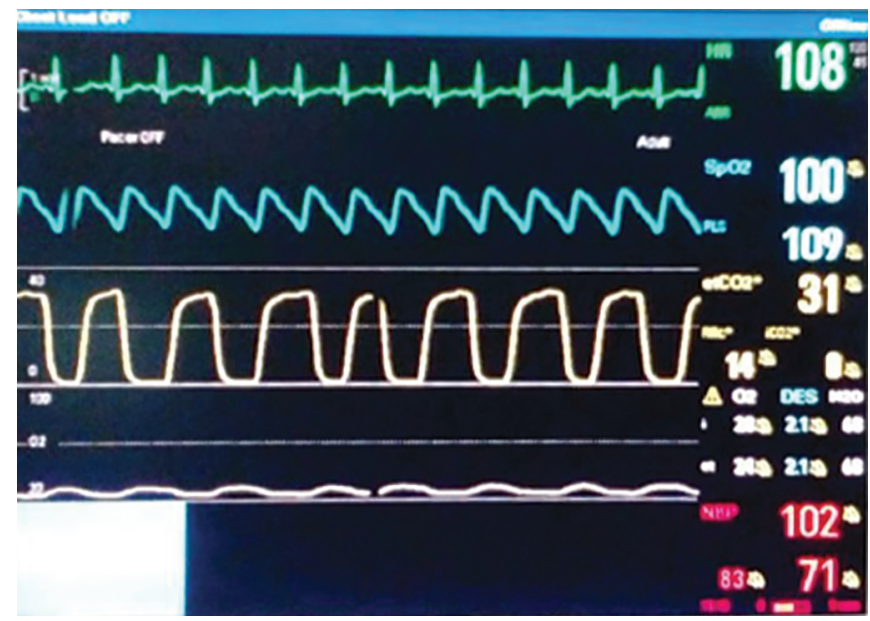

Fig. 2: Monitor showing vitals in the intraoperative period

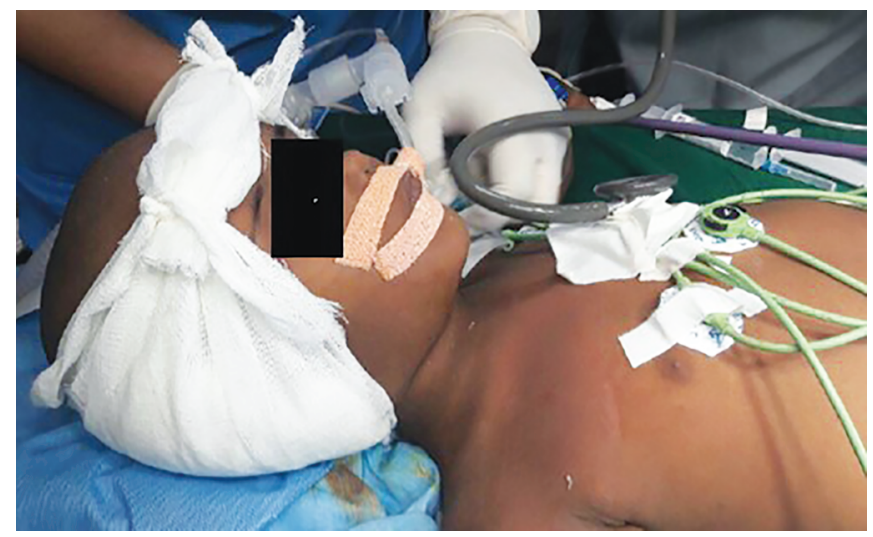

Fig. 4: Postoperative picture just before shifting patient to recovery room

Once the surgical procedure was complete, anesthesia was reversed with Inj. glycopyrrolate $0.15 \mathrm{mg}$ and Inj. neostigmine $0.75 \mathrm{mg}$ and extubated in the deep plane to prevent agitation (Figs 3 and 4). The patient was shifted to the post-anesthesia care unit. Inj. paracetamol $150 \mathrm{mg}$ was given intravenously 8th hourly for postoperative pain relief. The patient shifted to the ward on the 2 nd postoperative day. No hemodynamic variations were observed in the postoperative period and discharged on the 11th postoperative day.

\section{Discussion}

A cochlear implant is an electronic device used to restore hearing in patients with bilateral sensorineural hearing loss. It can transform speech and other sounds into electrical signals used to stimulate the existing fibers of the auditory nerve in the inner ear.

\section{Anesthetic Aspects}

Cochlear implant surgery is done under microscopic vision. Even very minimal bleeding in the surgical field will obscure the vision of the surgeon, so important to maintain a bloodless surgical field with stable intraoperative hemodynamics.

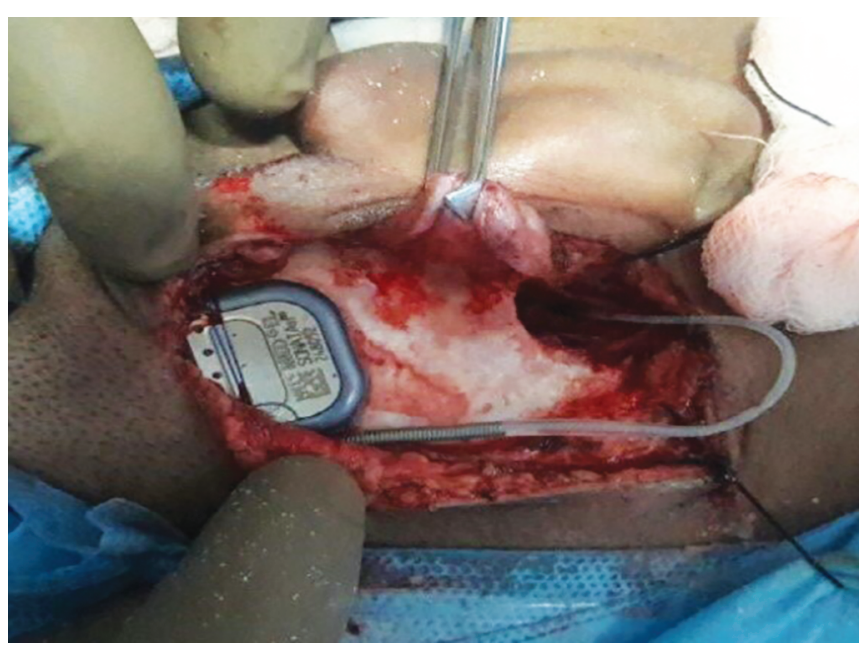

Fig. 3: Intraoperative picture showing the embedded cochlear implant

Anesthetic techniques should not interfere with the stimulation techniques used by the surgeons. Commonly used techniques are balanced general anesthesia, TIVA, and regional techniques.

Infants and children are vulnerable to hypothermia because of the large ratio of body surface area to weight, the thinness of the skin, and the limited ability to cope up with cold stress. It causes increased $\mathrm{O}_{2}$ consumption and metabolic acidosis. Addressing above mentioned, perioperative heat loss is vital. The surgical unit should be warmed to $270^{\circ} \mathrm{C}$ using a forced-air warmer, the child should be placed on a warm mattress to prevent heat loss. Warming is most effective; however, overheating must be avoided.

Facial nerve injury should be prevented during surgery and its patency should be rechecked intraoperatively, anesthesia can be maintained by propofol infusion during this step. So neuromuscular monitoring has an essential role in this surgery. It helps in assessing the depth of neuromuscular blockade, ensures proper medication dosage and timing, and thereby decreases the incidence of side effects. The use of depth of anesthesia monitors such as bispectral index (BIS) provides an additional advantage in maintaining light planes with a sufficient level of hypnosis. It helps in titrating the concentration of the inhalational agent.

At the end of the surgery, brainstem evoked response audiometry (BERA) is used to check the integrity of the implant is checked. Electrically evoked stapedius reflexes can also be checked which is done by checking the electrically elicited compound action potential $(E C A P)^{5}$ and ESRT or electrically elicited stapedius reflex threshold. ESRT suggests the maximum level of comfort. Electrically elicited compound action potential suggests the noise threshold. Many anesthetic agents can alter the ESRT causing wrong maximum comfort level values. ESRT is found to increase with the increasing concentration of the inhalational agent. Propofol and $\mathrm{N}_{2} \mathrm{O}$ have very minimal effects on ESRT.

The cochlear implant can be damaged by electrocautery discharges and so its use is discouraged once the implant is inserted.

Coughing and bucking toward the end of surgery is to be discouraged and after reversal, only spontaneous respiration is encouraged. So children are advised to be extubated in deeper planes and prevent emergence agitation. 


\section{Postoperative Care}

Postoperative nausea and vomiting or PONV is common in ear surgery. So measures have to be taken to reduce PONV. Palonosetron was also proved to be an efficacious antiemetic drug with a long duration of action. ${ }^{6}$

Postoperative analgesia can be maintained with opioid bolus like Inj. fentanyl or Inj. morphine. Intravenous or per rectal paracetamol helps in reducing doses of opioids used postoperatively. Thus, it prevents opioid-related side effects. ${ }^{7,8}$

Postoperative shivering can be reduced by the use of perioperative dexmedetomidine. ${ }^{9}$ Later patients need to be monitored in PACU till consciousness is regained.

\section{Complications}

Common anesthetic complications in the pediatric age group such as postoperative respiratory disturbances and laryngospasm should be kept in mind.

\section{Anesthetic Implications for Incidental Surgery in Patients with Cochlear Implant}

A major concern in incidental surgery in patients with a cochlear implant in situ is mainly the electrical interference caused by electrocautery and monopolar cautery. Its use should be avoided near the head and neck areas. The use of electroconvulsive therapy (ECT) in these patients should be avoided and so is the use of radiotherapy directly over the implant which can cause serious damage. MRI is also contraindicated in these patients as it can cause tissue damage in some along with some range of implant migration. However, if MRI is compulsory, then the external magnet can be removed through minor surgery, and thus making it MRI compatible, and later this magnet can be replaced postprocedure. $^{10}$

\section{References}

1. Eckenhoff JE. Some anatomic considerations of the infant larynx influencing endotracheal anaesthesia. Anestheiology 1951;12(4):401410. DOI: 10.1097/00000542-195107000-00001.

2. Selby IR, Rigg JD, Faragher B, et al. The incidence of minor sequelae following anaesthesia in children. Paediatr Anaesthesiol 1996;6(4):293. DOI: 10.1111/j.1460-9592.1996.tb00453.x.

3. Bonoli P, Grillone G, Fossa S, et al. Complications of pediatric anesthesia. Survey carried out by the study group SIAARTI for anaesthesia and intensive therapy in children. Minerva Anestesiol 1995;61(4):115.

4. Bajwa SJ, Jindal R, Kaur J, et al. Psychiatric diseases: need for an increased awareness among the anaesthesiologists. J Anaesthesiol Clin Pharmacol 2011;27(4):440-446. DOI: 10.4103/0970-9185. 86572.

5. Gordon K, Papsin BC, Harrison RV. Programming cochlear implant stimulation levels in infants and children with a combination of objective measures. Int J Audiol 2004;43:S28-S32.

6. Bajwa S, Bajwa S, Kaur J, et al. Palonosetron: a novel approach to control postoperative nausea and vomiting in day care surgery. Saudi J Anaesth 2011;5(1):19-24. DOI: 10.4103/1658-354X.76484.

7. Czarnecki ML, Ferrise AS, Jastrowski Mano KE, et al. Parent/nursecontrolled analgesia for children with developmental delay. Clin J Pain 2008;24(9):817-824. DOI: 10.1097/AJP.0b013e3181773b69.

8. Czarnecki ML, Salamon KS, Jastrowski Mano KE, et al. A preliminary report of parent/nurse-controlled analgesia (PNCA) in infants and preschoolers. Clin J Pain 2011;27(2):102-107. DOI: 10.1097/ AJP.0b013e3181f0972c.

9. Bajwa SJ, Gupta S, Kaur J, et al. Reduction in the incidence of shivering with perioperative dexmedetimidine: a randomized prospective study. J Anaesthesiol Clin Pharmacol 2012;28(1):86-91. DOI: 10.4103/0970-9185.92452.

10. Chakrabarthy A, Tarneja VK, Singh Adm VK, et al. Cochlear implant: anaesthesia challenges. Armed Forces Med J India 2004;60(4):351356. DOI: 10.1016/S0377-1237(04)80009-1. 